\title{
Predicting Atrial Fibrillation After Mitral Valve Replacement
}

\author{
Bulent Gorenek, M.D., Salih Bakar, Gulmira Kudaiberdieva, Yuksel Cavusoglu, \\ Omer Goktekin, Ahmet Unalir, Necmi Ata, and Bilgin Timuralp \\ From the Cardiology Department, Osmangazi University, Eskisehir,Turkey
}

Inhomogeneous prolongation of sinus impulses may predict the recurrence of atrial fibrillation (AF). ${ }^{1}$ Chang et al. ${ }^{2}$ investigated the relationship between $\mathrm{P}$-wave characteristics and AF development following cardiac coronary surgery (CCS). The paper presented by Balcetyte-Haris ${ }^{3}$ gave us important information about the prevention on post-CCS $\mathrm{AF}$, and showed that esmolol offered no advantages to standard beta-blockers in preventing $\mathrm{AF}$ after CCS in the patients with prolonged signalaveraged ECG P-wave duration. The data on AF occurrence, antiarrhythmic drugs and P-wave analysis are limited. In a study we observed that amiodarone, and decreasing P-wave dispersion detected by surface ECG, would improve the maintenance of sinus rhythm (SR) in patients with paroxysmal AF.

$\mathrm{AF}$ occurs frequently in severe mitral stenosis (MS), and as in CCS, many patients who had mitral valve replacement (MVR) suffer from postoperative AF. But, unfortunately, we know less about the mechanisms and predictors of AF development after MVR. So, we aimed to investigate the predictors of AF after MVR.

Data from 30 consecutive patients with MS in SR, who underwent MVR and developed postoperative AF (group I), were analyzed and compared with those of 30 consecutive patients who underwent MVR but did not experience postoperative AF (group II). The maximum $\mathrm{P}$-wave duration $\left(\mathrm{P}_{\max }\right)$, the minimum $\mathrm{P}$-wave duration $\left(\mathrm{P}_{\min }\right)$, and $\mathrm{P}$-wave dispersion $\left(\mathrm{P}_{\mathrm{d}}=\mathrm{P}_{\max }-\mathrm{P}_{\min }\right)$ were calculated from the preoperative 12-lead surface ECGs.
The patients in group I were older $(53 \pm 10$ vs $49 \pm 7 \mathrm{yr}, \mathrm{P}<0.05)$. The preoperative mean transmitral gradient was $20 \pm 5 \mathrm{mmHg}$ in group I, and $18 \pm 6 \mathrm{mmHg}$ in group II $(\mathrm{P}>0.05)$. The patients in group I had a larger left atrium diameter (LAD, $64 \pm 5$ vs $53 \pm 6 \mathrm{~mm}, \mathrm{P}<0.001)$. Preoperative mitral valve area detected by planimetry was $1.1 \pm$ $0.4 \mathrm{~cm}^{2}$ in group I and $1.2 \pm 0.3 \mathrm{~cm}^{2}$ in group II $(\mathrm{P}>$ $0.05)$. Left ventricular ejection fraction was not different in the two groups. The preoperative P-wave dispersion was significantly higher in group I ( $53 \pm$ 10 vs $39 \pm 9 \mathrm{~mm}, \mathrm{P}<0.001$ ).

These results suggest that older age, greater LAD, and $\mathrm{P}$-wave dispersion are the important predictors of AF after MVR. But as is CCS, further studies with a larger number of patients are required for understanding the mechanisms and treatment of AF after MVR.

\section{REFERENCES}

1. Dilaveris PE, Gialafos EJ, Sideris SK, et al. Simple electrocardiographic markers for the prediction of paroxysmal idiopathic atrial fibrillation. Am Heart J 1998;135:733738.

2. Chang CM, Lee $\mathrm{SH}_{1} \mathrm{Lu} \mathrm{MJ}$, et al. The role of $\mathrm{P}$ wave in prediction of atrial fibrillation after coronary artery surgery. Int J Cardiol 1999;68(30):3-8.

3. Balcetyte-Haris N, Tamis JE, Homel $\mathrm{P}$, et al. Randomized study of early intravenous esmolol versus oral betablockers in preventing post-CABG atrial fibrillation in high risk patients identified by signal-averaged ECG: Results of a pilot study. Ann Noninv Electrocardiol 2002;7:8991.

Address for reprints: Bulent Gorenek, M.D., Koprubasi-Eskisehir, 115 26311,Turkey. Tel: 0090222 2392476; Fax: 00902222395370 ; E-mail:bgorenek@hotmail.com 